\title{
Mechanical and Tribological Features of the 90MnCrV8 Steel after Plasma Nitriding
}

\author{
Michal Krbat’a ${ }^{1}$, Jozef Majerík ${ }^{1}$, Igor Barényi ${ }^{1}$, Ivana Mikušová1, David Kusmič² \\ ${ }^{1}$ Faculty of special technology, Alexander Dubček University in Trenčin. Pri parku 1, 91105 Trenčín. Slovak Republic. \\ E-mail: michal.krbata@tnuni.sk \\ ${ }^{2}$ Faculty of military technology, University of Defence, Kounicova 65, 66210 Brno. Czech Republic. E-mail: david.kus- \\ mic@unob.cz
}

The paper deals with the change in mechanical properties and wear of 90MnCrV8 universal tool steel after plasma nitriding, which is widely used to produce cutting tools with good durability and low operating costs. Plasma nitriding was performed at a temperature of $500{ }^{\circ} \mathrm{C}$ for 10 hour period in a standard $\mathrm{N} 2 / \mathrm{H} 2$ atmosphere with $1: 3$ gases ratio. Microstructure, phase structure, thickness of a nitriding layer and surface roughness of samples were measured with optical microscopes and a profilemeter. Verification of a chemical composition was carried out on the BAS TASMAN Q4 device. Wear resistance was measured on a universal TRIBOLAB UTM 3 tribometer, through a "pin on disc" method. The results of experiments have shown that plasma nitriding process, significantly improves the mechanical and tribological properties of selected materials.

Keywords: Plasma nitriding, Microhardness, Friction coefficient, Pin on disc.

\section{Introduction}

The $90 \mathrm{MnCrV} 8$ tool steel is suitable for the plasma nitriding process due to its chemical composition. This steel has a wide range of applications for the production of universal cutting tools. Authors Studený et al. [1] solved importance of diffusion process on the fatigue life of this type of steel in their scientific research. Investigations with the same workpiece material were also realized by the authors [9, 10,12]. Authors Pilch at al. [2] solved the corrosion resistance of turbocharger stator after plasma nitriding process. The authors $[4,5]$ also studied and dealt with the same problem of plasma nitriding.

Tribology of these parts plays an important role in their functionality and lifetime. Tribological problems can often be solved with a surface finish. Authors Doan et al. [3] have dealt with their research with the improvement of wear resistance for $\mathrm{C} 45$ steel using plasma nitriding, nitrocarburizing and nitriding. Also the authors Dubovská and Majerík [7] conducted the research analysis of surface finish and wear on the special tribological device. The effect of nitrogen on surface morphology of layers was solved by the authors Pokorný et al. [6].

Plasma nitriding, with regard to many advantages unlike common kinds of nitriding found an increasing industrial application $[5,11]$. The main problem of nitridations in salt bathes is connected with a toxicity of cyanide salts. Traditional gaseous nitriding requires a longer time for treatment to obtain a needed nitridation depth. Direct current of plasma nitriding (DCPN) has been recently one of conventional treatment of a surface finish being used in industry aiming to improve mechanical features and wear resistance of mechanical engineering materials. Various layers may rise on a surface due to a plasma nitriding. These layers are classified by composition of particular phases. With respect to a steel composition, its layer is mainly composed of ferrous nitrides $\left(\gamma^{\prime}-\mathrm{Fe}_{4} \mathrm{~N}\right.$ or $\left.\varepsilon-\mathrm{Fe}_{2-3} \mathrm{~N}\right)$ and nitrides of alloying elements.

Research studies showed that a microstructure of a nitriding layer can be affected with a change of parameters of a nitriding process, as temperature, time and plasma composition of the gas. Changes in a microstructure of nitriding layer effect mechanical and tribological features of the material, as surface hardness, wear resistance and endurance strength $[2,4,8]$. For a diffusion controlled growth, a thickness of a nitriding layer increases with temperature and nitridation time [6]. However a maximum surface hardness is achieved only at a certain nitridation time and temperature. Previous studies showed that a chemical potential of nitrogen is important a plasma nitriding of steels.

\section{Experimental details}

The samples were annealed. Process of a plasma nitriding was carried out on the Rubig 60/60 device. The parameters of a plasma nitriding were chosen so that a nitriding layer is reached as thick and as hard as possible, Tab. 1.

Thermally treated and surface finished steel samples were numerically marked. Chemical composition of given steel was verified through a BAS TASMAN Q4 device and subsequently it was compared with the DIN 90MnCrV8 technical standard Tab. 2.

Measurements of microhardness and thickness of a nitriding diffusion layer were taken on each sample through a Vickers method. Impressing of a diamond pyramid under vertex angle of $136^{\circ}$ is essence of the method. The LECO M400H microhardnessmeter will be used to verify and to compare achieved results before and after plasma nitriding. The load force will be $0.5 \mathrm{~N}$ and force action time in accordance with DIN 50190 standard will be $10 \mathrm{sec}$. The measurements of microhardness will be taken on a cross-section of a nitrided sample, upright from a surface to the material core. The achieved values on hardness will be displayed as a function of a distance from a surface. Thickness of a nitride layer will be taken on 18 imprints and 5 imprints in the material core. Limit value in terms of this standard is a hardness value, designated as limit hardness GH) and it is indicated as the Vickers hardness and it applies:

$\mathrm{GH}=$ average measured value in a core $+50 \mathrm{HV}$ (rounded to 10HV)

Metallographic analysis is based on a polishing of 
samples and a subsequent etching with Nital. Etching of samples brings up their microstructures. We make out matallographical pictures of all samples with the Olympus GX51 optical matallographical microscope. With the microscope we can monitor a size of a white layer as well as an approximated size of a diffusion layer. Then we can assess a resulting structure of a diffusion layer as well as a basic material.

Roughness of surface was measured on the Talisurf CCI Lite 3D device. All samples had been grinded on a mag-netic grinder with $0.001 \mathrm{~mm}$ precision before plasma nitriding and marking. Surface roughness was measured before and after plasma nitriding aiming to define changes of roughness.

Measurement of wear was executed on the BRUKER UTM 3 device using, pin of disc method. This method is based on imprinting a firmly gripped body in a ball shape into a testing material in a disc shape, being rotated with constant revolutions. The testing ball was made of the 440-C stainless steel with a $6.35 \mathrm{~mm}$ diameter and 746 $\mathrm{HV}$ hardness. The measurements were taken from 6 samples at 3 loads and three measurement radiuses. The Measurement radiuses for each sample are shown in Tab. 3.

Tab. 1 The parameters of plasma nitriding

\begin{tabular}{|c|c|c|c|c|}
\hline Pressure [mbar] & Voltage [V] & Atmosphere PN [1/3] & Temperature PN $\left[{ }^{\circ} \mathrm{C}\right]$ & Time PN [hour] \\
\hline 2.8 & 700 & N2 / H2 & 500 & 10 \\
\hline
\end{tabular}

Tab. 2 Chemical composition 90MnCrV8 steel [in wt. \%]

\begin{tabular}{|c|c|c|c|c|c|c|c|c|}
\hline Element & $\mathrm{C}$ & $\mathrm{Si}$ & $\mathrm{Mn}$ & $\mathrm{P}$ & $\mathrm{S}$ & $\mathrm{Cr}$ & $\mathrm{Mo}$ & $\mathrm{V}$ \\
\hline \multirow{2}{*}{ DIN Standard } & $0.27-$ & $\max$ & $0.40-$ & $\max$ & $\max$ & $2.30-$ & $0.15-$ & $0.10-$ \\
& 0.34 & 0.40 & 0.70 & 0.025 & 0.035 & 2.70 & 0.25 & 0.20 \\
\hline BAS Tasman Q4 & 0.34 & 0.39 & 0.69 & - & 0.034 & 2.38 & 0.21 & 0.20 \\
\hline
\end{tabular}

Tab. 3 Measurement parameters for tribology

\begin{tabular}{|c|c|c|c|c|c|}
\hline $\begin{array}{l}\text { Identifications } \\
\text { of the samples }\end{array}$ & Heat treatment & Turning radius & Load $[\mathrm{N}]$ & $\begin{array}{c}\text { Rotation speed } \\
{[\mathrm{rpm}]}\end{array}$ & $\begin{array}{l}\text { Measuring time } \\
\text { [min] }\end{array}$ \\
\hline \multirow[t]{3}{*}{ 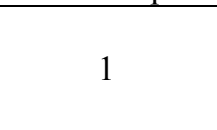 } & \multirow{3}{*}{ Annealed } & 19 & 50 & \multirow{3}{*}{250} & \multirow{3}{*}{20} \\
\hline & & 21 & 50 & & \\
\hline & & 23 & 50 & & \\
\hline \multirow{3}{*}{2} & \multirow{3}{*}{ Annealed } & 19 & 100 & \multirow{3}{*}{250} & \multirow{3}{*}{20} \\
\hline & & 21 & 100 & & \\
\hline & & 23 & 100 & & \\
\hline \multirow{3}{*}{3} & \multirow{3}{*}{ Annealed } & 19 & 150 & \multirow{3}{*}{250} & \multirow{3}{*}{20} \\
\hline & & 21 & 150 & & \\
\hline & & 23 & 150 & & \\
\hline \multirow{3}{*}{4} & \multirow{3}{*}{ Plasma nitriding } & 19 & 50 & \multirow{3}{*}{250} & \multirow{3}{*}{20} \\
\hline & & 21 & 50 & & \\
\hline & & 23 & 50 & & \\
\hline \multirow{3}{*}{5} & \multirow{3}{*}{ Plasma nitriding } & 19 & 100 & \multirow{3}{*}{250} & \multirow{3}{*}{20} \\
\hline & & 21 & 100 & & \\
\hline & & 23 & 100 & & \\
\hline \multirow{3}{*}{6} & \multirow{3}{*}{ Plasma nitriding } & 19 & 150 & \multirow{3}{*}{250} & \multirow{3}{*}{20} \\
\hline & & 21 & 150 & & \\
\hline & & 23 & 150 & & \\
\hline
\end{tabular}

\section{Metallographic structure}

There is a microstructure of the $90 \mathrm{CrMoV} 8$ steel, which can be seen in the Fig. 1, in a treated condition and after having etched $2 \% \mathrm{Ni}$-tal and it was assessed as a perlite and secondary cement. Perlite occurs both in lamellar and globular form. An average micro hardness had a value of $270 \mathrm{HV}$. After plasma nitriding on a metallographic section there were expressly visible and measurable only thicknesses of white layers. There is a coherent and relatively even white layer of nitrides on the samples surface. Under a white layer there is a diffusion layer.

The white layer with an average thickness $6.3 \mu \mathrm{m}$ was created at the plasma nitriding temperature of the $500{ }^{\circ} \mathrm{C}$ and nitriding period of 10 hours. Optically is recognizable on the sample surface. In this case, the diffusion layer is not optically distinct from the core of the material.

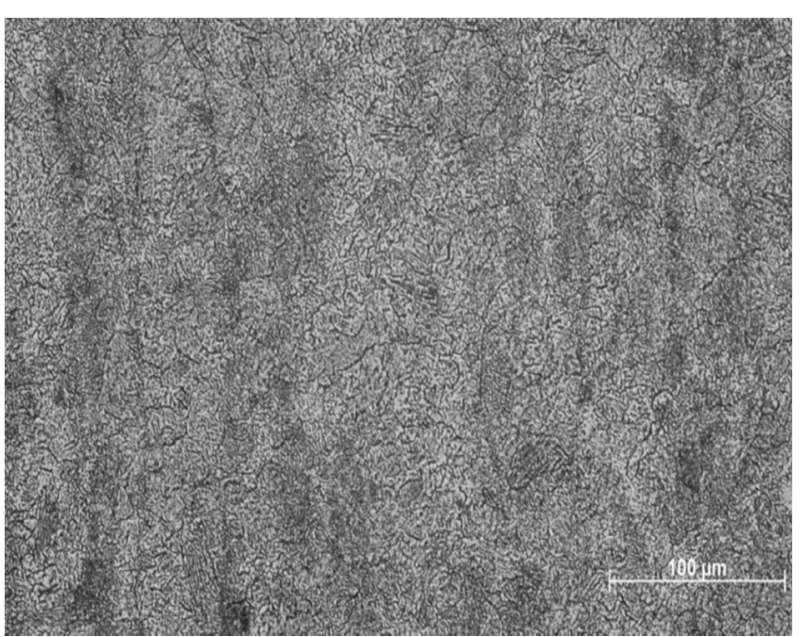

Fig. 1 Cross-sectional microstructure 


\section{Profiles of micro hardness and surface rou- ghness}

The Tab. 4 was developed from the measurement results, where thicknesses of particular diffusion layers of steels are documented. In the Tab. 4 there are also displayed the values of thicknesses of white layers on particular samples. From the table it is obvious that the results are the same for thickness of nitriding layer as well as for the white layer. At the sample 5 a minimum increase of a diffusion layer is visible, which shows no significant change in subsequent measurements. We can note that all samples had passed through plasma nitriding process at the same conditions and a risen diffusion layer is the same on all samples.

Tab. 4 The results of thickness diffusion and white layers

\begin{tabular}{|c|c|c|}
\hline $\begin{array}{c}\text { Identification } \\
\text { of the sample }\end{array}$ & $\begin{array}{c}\text { Thickness of } \\
\text { diffusion layer } \\
{[\mathrm{mm}]}\end{array}$ & $\begin{array}{c}\text { Thickness of } \\
\text { white layer } \\
{[\mathrm{mm}]}\end{array}$ \\
\hline $\mathbf{4}$ & 0.38 & 6.3 \\
\hline $\mathbf{5}$ & 0.37 & 6.1 \\
\hline $\mathbf{6}$ & 0.38 & 6.5 \\
\hline
\end{tabular}

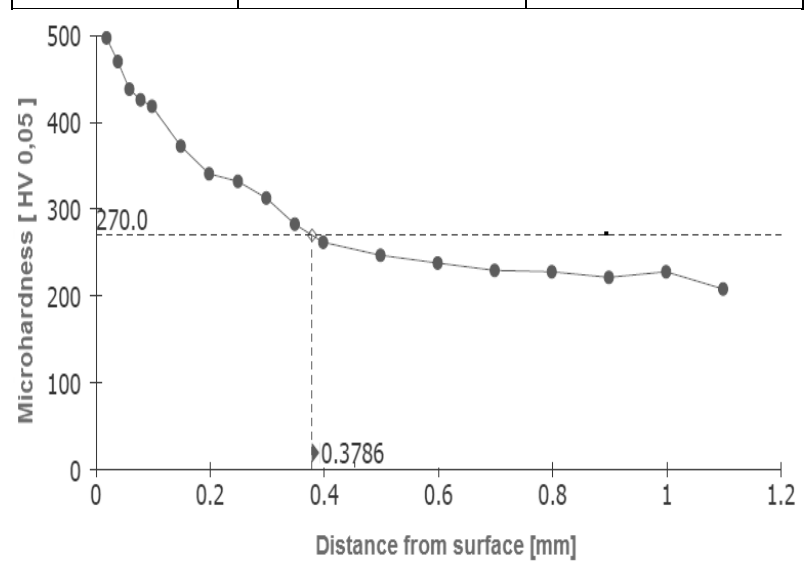

Fig. 2 Thickness of the nitrided layer in sample 5

Qualitative data on roughness are shown in the Fig. 3. Surface roughness on all samples, that have passed through the plasma nitriding process, are deteriorated in average by $25 \%$ comparing with samples without plasma nitriding. This deterioration was caused by a dedusting process and due to a rise of a new nitride surface layer.

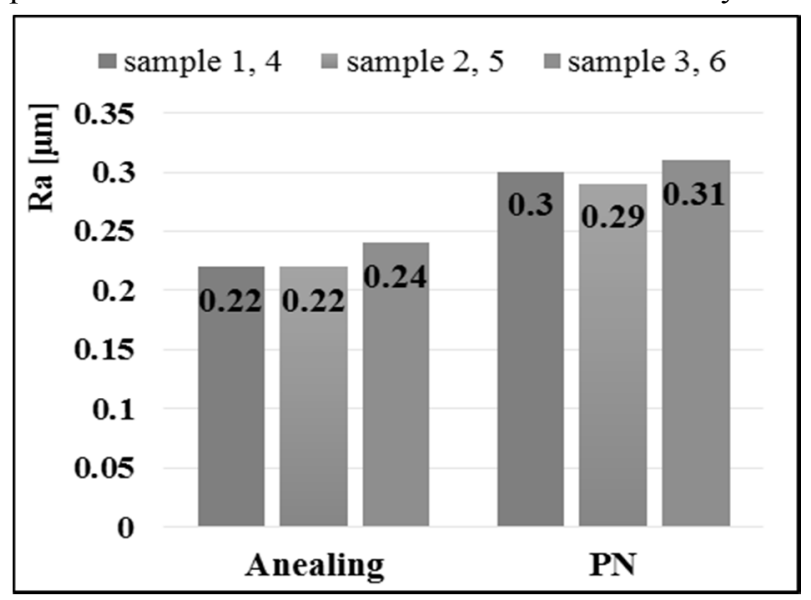

Fig. 3 Surface roughness $90 \mathrm{MnCrV} 8$ before and after plasma nitriding

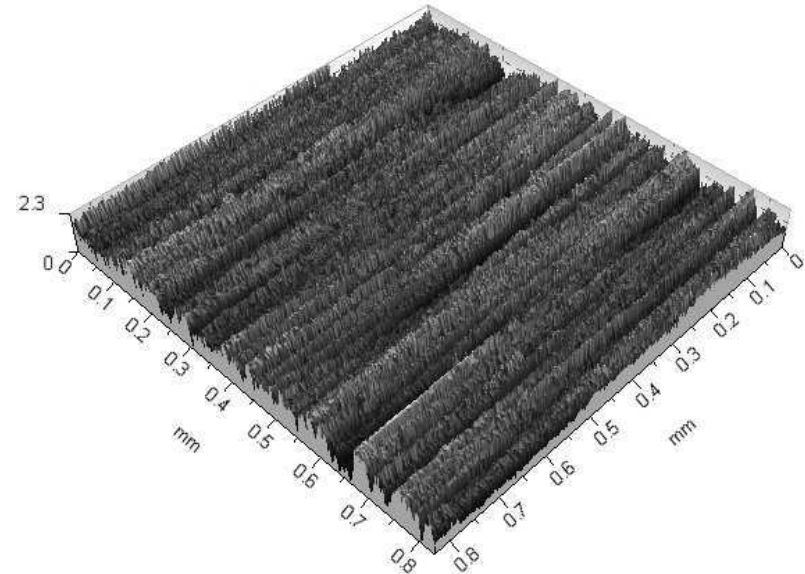

Fig. 4 3D profile steel $90 \mathrm{MnCrV8}$ without application of plasma nitriding; $\mathrm{Sa} 0,23 \mu \mathrm{m}$

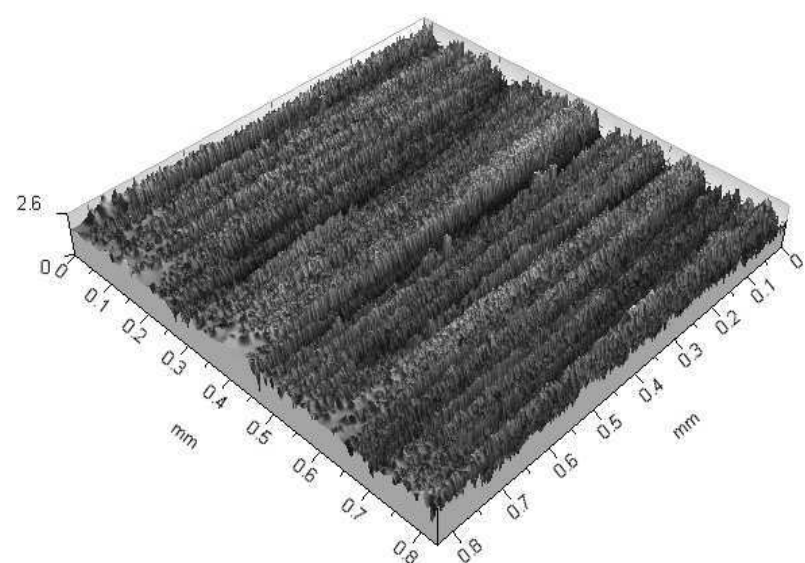

Fig. 53 profile of the steel $90 \mathrm{MnCrV8}$ nitrided at 500 ${ }^{\circ} \mathrm{C}$ and time of 10 hours; $\mathrm{Sa} 0,30 \mu \mathrm{m}$

\section{Wear resistance}

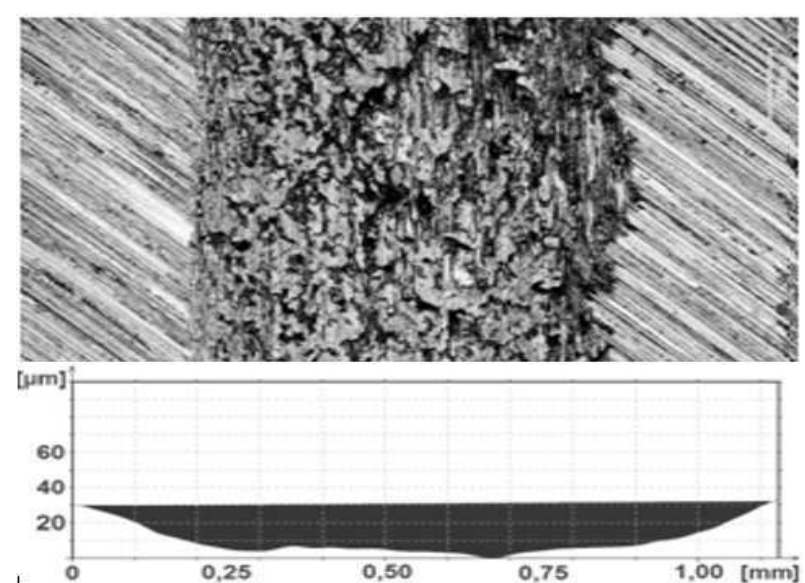

Fig. 6 Surface profiles of wear and depth tracks before $P N, C O F$ 0,59, h $31 \mu \mathrm{m}$

The results on wear before and after plasma nitriding are shown in the Fig. 4, 5. In the picture we can distinctly see different traces after wearing. The wear shown in the Fig. 6, points at a high rate of wear, as this sample had passed only through a basic type of a thermal treatment. For the next samples (Fig. 7, 8, 9) significant improvement of a surface profile occurred and these samples were plasma nitrided and they featured with much higher quality of surface. It can make a comparison, which can 
be seen in the (Fig. 10), between all the measurements of wear at different load parameters and different radiuses of rotation. The depth of wear was measured with profile meter and the results are displayed on a plot in the (Fig. 11). Each measurement of a depth was taken on four different places and subsequently an average depth of an imprint was defined. The results expressly point at excellent mechanical features of plasma nitrided samples, as their depth of the imprint was ranging only in several micrometers comparing with tempered samples.
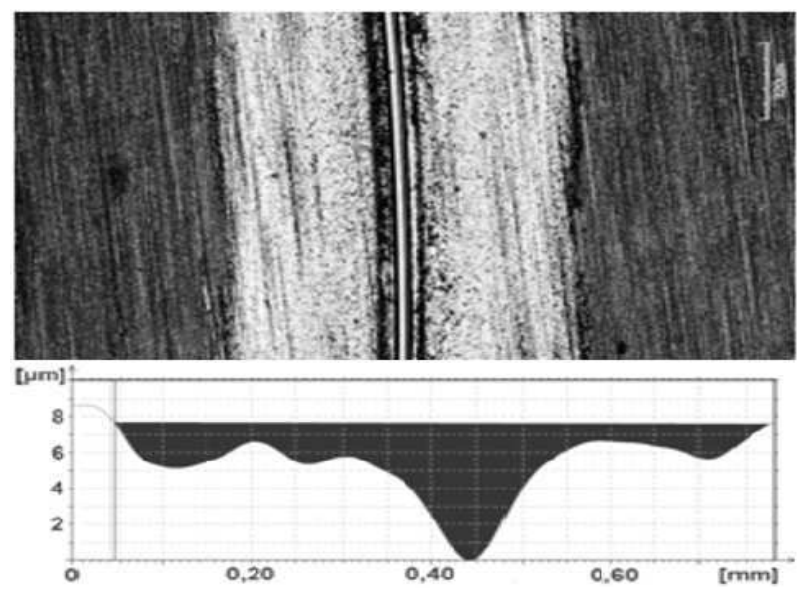

Fig. 7 Surface profiles of wear and depth tracks after $P N, C O F$ 0,42, h 7,2 $\mu \mathrm{m}$,

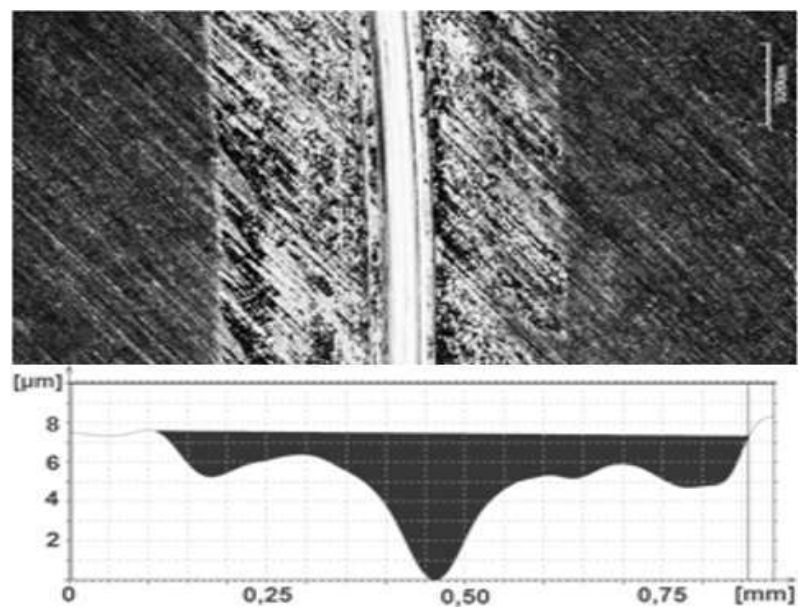

Fig. 8 Surface profiles of wear and depth tracks after PN COF 0,40, h 7,6 $\mu \mathrm{m}$,
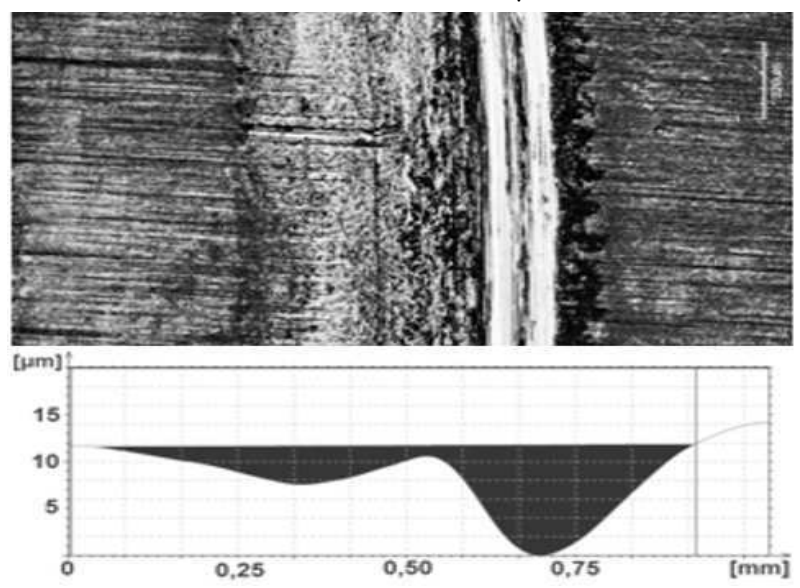

Fig. 9 Surface profiles of wear and depth tracks after PN COF 0,39, h 10,1 $\mu \mathrm{m}$

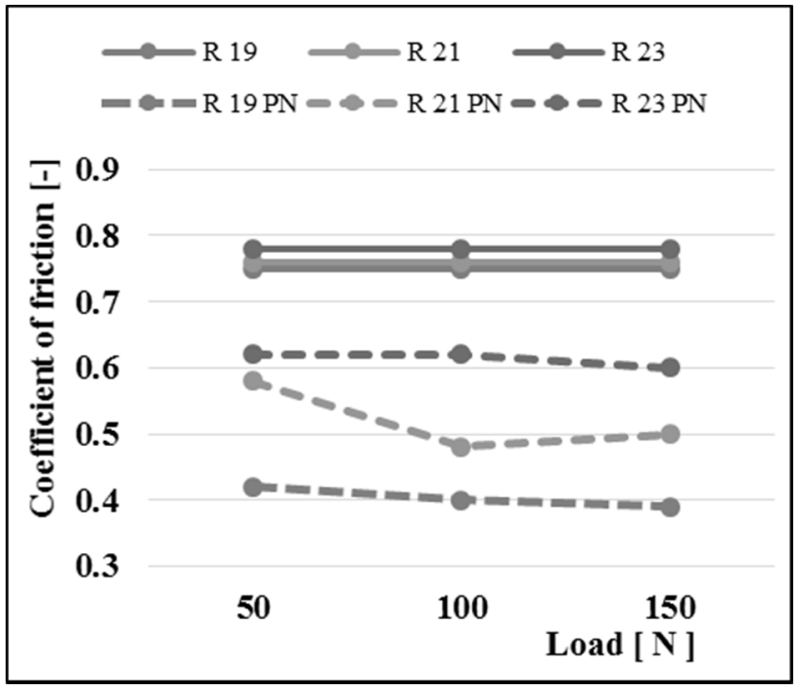

Fig. 10 Comparison of friction coefficient for all samples

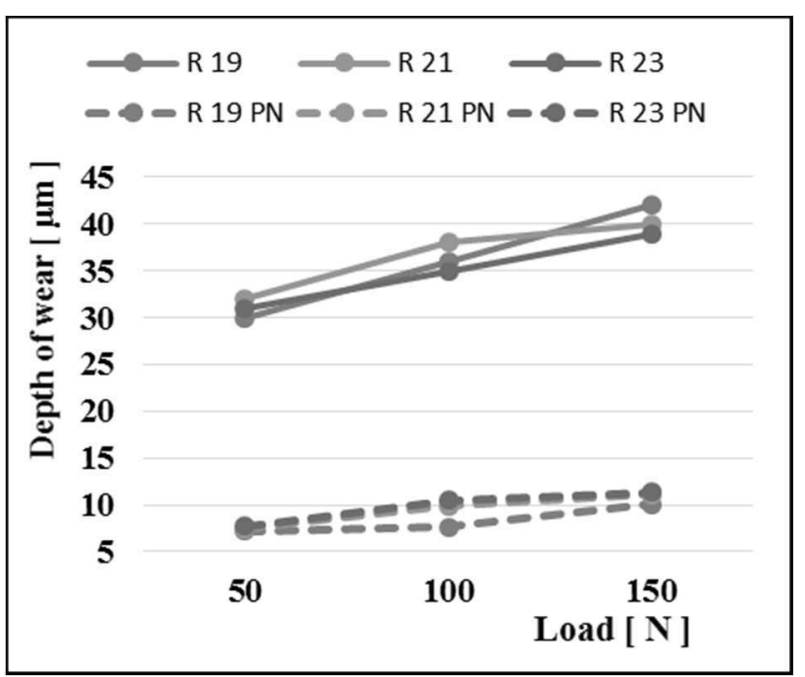

Fig. 11 Comparison indention depth in all samples

\section{Conclusion}

All measurements were focused on a study of the 90MnCrV8 structural nitride steel. Plasma nitriding was carried out at standard conditions and parameters were chosen in such a way to achieve the best possible diffusion layer. The research brought us some valuable information about mechanical features of the $90 \mathrm{MnCrV} 8$ steel. From a study of a microstructure and based on results the following conclusions can be made:

- The 90CrMoV8 tool steel is suitable for a plasma nitriding process due to is chemical composition and the results of microstructure point at a rise of a diffusion layer of $0.38 \mu \mathrm{m}$ thickness, mainly composed of $\varepsilon$ - phase (Fe2-3N).

- A surface hardness of tempered samples had a value of $270 \mathrm{HV}$, it increased after plasma nitriding in average to a value of $500 \mathrm{HV}$, i.e.we can note, that plasma nitriding significantly increases a surface hardness and so the lifetime as well, as the majority of degra- 
dation processes start spreading from the surface into the material core.

- Material roughness before nitriding process was ranging on the level of $0.23 \mu \mathrm{m}$, after plasma nitriding the sur-face quality got worse by $25 \%$ to the value of $0.30 \mu \mathrm{m}$. Such deterioration is caused by a dedusting process, when the nitride cations bombard a material surface and subsequently atoms of various elements, being on a material surface are shot out.

- Resistance to wear plays one of the most important roles in a material lifecycle. Plasma nitriding process significantly decreases a friction coefficient. The friction coefficient decreased at plasma nitrided samples comparing with samples that had passed only a basic thermal treatment at all three loads. The same results are obtained from an imprint depth, left by a measuring ball. These findings are connected with a rise of a hard diffusion layer on a surface after a plasma nitriding process.

From the results of the experiment we can state that a plasma nitriding improves a quality of mechanical features of the $90 \mathrm{MnCrV} 8$ steel except of material roughness. It brings a great benefit in area of improvement of tribological features of materials as well as their application in various sectors of mechanical engineering industry and cutting tools.

\section{Acknowledgement}

This work was supported by the Slovak Research and Development Agency under the contract No. APVV-150710.

\section{References}

[1] Z. STUDENÝ, D. DOBROCKÝ, Z. POKORNÝ (2017). Importance of diffusion process on the fatigue life of steel, Manufacturing Technology, Vol. 17, 2017, Issue 1, p. 94-99.

[2] O. PILCH, P. FALTEJSEK, V. HRUBÝ, M. KRBATॅA (2017). The corrosion resistance of turbocharger stator after plasma nitriding process, Manufacturing Technology, Vol. 17, 2017, Issue 3, p. 360-364.

[3] T. V. DOAN, D. KUSMIČ, M. POSPÍCHAL, D. DOBROCKÝ (2017). Improvement of wear resistance for C45 steel using plasma nitriding, nitrocarburizing and nitriding/ manganese phosphating duplex treatment, In: IOP Conference Series:
Materials Science and Engineering, Vol. 179, 2017, Issue 1Article number 012017.

[4] D. KUSMIČ, T.V. DOAN, O. PILCH, M. KRBAŤA (2016). Corrosion resistance and tribological properties of plasma nitrided and tenifered 42CrMo4 steel, In: METAL 2016 - 25th Anniversary International Conference on Metallurgy and Materials, Conference Proceedings, 2016, p. 1103-1108.

[5] M. UlUTAN, K. KILIÇAY, E. KAYA, I. BAYAR (2016). Plasma transferred arc surface modification of atmospheric plasma sprayed ceramic coatings, Journal of Mechanical Science and Technology, Vol. 30, 2016, Issue 8, p. 3813-3818.

[6] Z. POKORNÝ, V. HRUBÝ, Z. STUDENÝ (2016). Effect of nitrogen on surface morphology of layers, Kovové Materiály, Vol. 54, 2016, No. 2.

[7] R. DUBOVSKÁ, J. MAJERÍK (2015). The research analysis of surface finish and wear on the special tribological device, Procedia Engineering, Vol. 100, 2015, p. 730-736.

[8] D. LANDEK, B. LISCIC, T. FILETIN, T. LUBBEN, D. LISJAK (2009). Hardenability testing and simulation of gas-quenched steel, Materials and Manufacturing Processes, Vol. 24, 2009, Issue 7-8, p. 868-872.

[9] S. EKINOVIČ, S. DOLINŠEK, E. BEGOVIČ (2005). Machinability of $90 \mathrm{MnCrV8}$ steel during high-speed machining, Journal of Materials Processing Technology, Vol. 162-163, 2005, No. 1-3, p. 603-608.

[10] N. AXÉN, K H. ZUM GAHR (1992). Abrasive wear of TiC-steel composite clad layers on tool steel. Wear, Vol. 157, 1992, Issue 1, p. 189 201.

[11] F. TAYLAN, O. ÇOLAK, M. C.KAYACAN (2011). Investigation of TiN Coated CBN and CBN cutting tool performance in hard milling application, Strojniski Vestnik/Journal of Mechanical Engineering, Vol. 57, 2011, Issue 5, p. 417424.

[12] M. J. BARRENA, J. M. GÓMEZ DE SALAZAR, L. MATESANZ (2010). Interfacial microstructure and mechanical strength of WC$\mathrm{Co} / 90 \mathrm{MnCrV} 8$ cold work tool steel diffusion bonded joint with $\mathrm{Cu} / \mathrm{Ni}$ electroplated interlayer, $\mathrm{Ma}$ terials and Design, Vol. 31, 2010, Issue 7, p. 3389-3394. 